\title{
Prevalence and nature of psychiatric referrals from Intensive Care Unit of a teaching hospital
}

\author{
Poudel $\mathbf{R}^{1}$, Belbase $\mathbf{M}^{\mathbf{2}}$
}

1. Lecturer, Department of Psychiatry, NGMC-TH, Kohalpur, Nepal. 2. Associate Professor, Department of Psychiatry, NGMC-TH, Kohalpur, Nepal.

E-mail *Corresponding author : reet.poudel@gmail.com

\begin{abstract}
Introduction: Patients admitted to intensive care unit (ICU) are diagnosed with various disorders. There is limited literature on the prevalence of psychiatry disorders in patients admitted to ICU. The aim of the study was toestimate the prevalence and nature of psychiatric referrals from ICU.

Material And Method: Hundred consecutive patient admitted to the ICU (both medical ICU and CCU)in Nepalgunj Medical College Teaching Hospital (NGMCTH), Kohalpur, Nepal and referred to psychiatry department were enrolled for the study. Study was conducted from October 14, 2017 to June 14, 2018. Informed consent was taken and patients were interviewed by two psychiatrists in different occasions separately and other relevant history was obtained from next of kin. Socio-demographic variables, referring department, reason for referral, purpose of referral, major symptom for referral were the major variables. Psychiatric diagnosis was made using the ICD-10. Data was analyzed using Statistical Package for the Social Sciences (SPSS) version 21.0 for Windows.

Results: During the study period the total patients admitted to the ICU was 787 among which 100 were referred to psychiatry department. Psychiatry referral rate was $7.87 \%$, average patients referred were 2.4 per day. Psychiatry morbidity was $8.11 \%$. The mean age was $36.87+12.81$ years. Most of the patients were female, and from urban background. The most common diagnosis was alcohol use disorder (AUD) followed by intentional self harm (ISH) and delirium respectively. Organic disorder and dissociative disorder were the only disorders significantly associated $(p<0.05)$ with the age of the patient. AUD $(p=0.007)$ and ISH $(p=0.011)$ was common in female compared to males and the difference was statistically significant.
\end{abstract}

Conclusion: Psychiatric referral rate and psychiatry morbidity was low.

Keywords: ICU, Psychiatry, Referral

\section{INTRODUCTION}

Intensive Care Unit (ICU) is a ward where physicians and nurses observe and treat desperately ill patients 24 hours a day and it serves patients from all branches of medicine. The primary goal of ICU is to restore and maintain the function of vital organs, enhancing the chance of survival. ${ }^{1}$ In recent years ICU has been an integral part of multispecialty hospital where medical and surgical care can be given under constant supervision. Patient admitted to ICU generally present with chronic or life threatening physical conditions who may need various life supports and different medications including sedatives and analgesics. These days patients with psychiatric disorders are also primarily admitted to ICU for round the clock care, while on the other hand, ICU stay itself can lead to various psychiatric disorders including anxiety $^{2}$, depression ${ }^{3}$ and post-traumatic stress disorder. ${ }^{4}$

Studies from all over the world have shown a direct association of mental disorders and 
severity of chronic physical conditions in people of all age group..$^{5-7}$ In a multispecialty hospital, psychiatry consultations are sought by various departments including ICU. Psychiatric morbidity is common in patients admitted in ICU 8,9 and psychiatry consultations are sought for various conditions including delirium ${ }^{10}$, substance dependence ${ }^{11}$ and other psychiatric disorders ${ }^{9}$. There are only a few publications regarding studies conducted in ICU from Nepal and publications regarding psychiatric disorders in ICU patients are lacking.12,13 Most of the studies conducted in Nepal regarding psychiatry referrals are based on patients referred from various other departments to psychiatry. We could not find any literature from Nepal related to prevalence of psychiatry disorders in ICU and nature of psychiatric referrals from ICU. Present study was undertaken to determine the prevalence and nature of psychiatric disorders in ICU.

\section{MATERIAL AND METHOD}

The study was conducted in Nepalgunj Medical College Teaching Hospital (NGMCTH), Kolhapur, Nepal. NGMCTH is situated in Banke district of Nepal and is one of the largest hospitals in West Nepal. The ICUof the hospital consists of 17 bedded Medical ICU and 6 bedded Cardiac Care Unit (CCU). Hundred consecutive patient admitted to the ICU (both medical ICU and CCU) and referred to psychiatry department were enrolled for the study. It took 240 days; from October 14, 2017 to June 14, 2018 to enroll all the patients. Informed consent was taken from the patient or next to kin. The patients were interviewed by two psychiatrists in different occasions separately and other relevant history was obtained from next of kin. Socio-demographic variables, referring department, reason for referral, purpose of referral, major symptom for referral were the major variables. Psychiatric diagnosis was made using the ICD-10.14 Data was analyzed using Statistical Package for the Social Sciences (SPSS) version 21.0 for Windows.

\section{RESULT}

During the study period the total patients admitted to the ICU was 787 among which 100 were referred to psychiatry department. Psychiatry referral rate was $7.87 \%$. Average patients referred were 2.4 per day. Among 100 patients referred, 97 of them had psychiatric morbidity and assuming psychiatry disorders absent in non-referred patients, psychiatry morbidity was found to be $8.11 \%$. Table 1 shows the sociodemographic characteristics of the subjects. Male constituted $43 \%$ of the subjects while female $57 \%$. Majority of the subjects were from urban background (59\%) and $97 \%$ of the subjects were Hindu by religion. Seventy six percent of the patient had some form of education.

Table 1: Socio-demographic Characteristics Of the Patients

\begin{tabular}{|l|l|l|}
\hline Characteristics & Frequency/\% \\
\hline \multirow{2}{*}{ Sex } & Male & 43 \\
\cline { 2 - 3 } & Female & 57 \\
\hline \multirow{2}{*}{$\begin{array}{l}\text { Place of } \\
\text { Residence }\end{array}$} & Urban & 59 \\
\cline { 2 - 3 } & Rural & 41 \\
\hline \multirow{2}{*}{ Religion } & Hindu & 97 \\
\cline { 2 - 3 } & Muslim & 3 \\
\hline \multirow{2}{*}{ Education } & No education & 24 \\
\cline { 2 - 3 } & Some education & 76 \\
\hline
\end{tabular}

Table 2 shows the distribution of subjects based on age group and diagnosis. More than half of the patients were aged between 30 to 49 years. The mean age was $36.87+12.81$ years. The most common diagnosis was alcohol use disorder(22\%) followed by intentional self harm $(20 \%)$ and delirium $(19 \%)$ respectively. There was no statistically significant association of these three disorders with age of the patient. Organic disorder and dissociative disorder were the only disorders significantly associated $(p<0.05)$ with the age of the patient.

Table 3 shows the distribution of subjects based on diagnosis and age. Alcohol use disorder (AUD) was observed in 15 males and 7 females and the difference was statistically significant $(p=0.007)$. Similarly ISH was common in female compared to males and the difference was statistically significant (17 vs $3 ; \mathrm{p}=0.011$ ). 
Table 2:Distribution of subjects according to diagnosis and age

\begin{tabular}{|l|r|r|r|r|r|r|r|r|}
\hline \multirow{2}{*}{ Diagnosis } & \multicolumn{9}{|c|}{ Age Range in years; } & $\begin{array}{r}\text { Total } \\
(\%)\end{array}$ & p value \\
\cline { 2 - 9 } & $10-19$ & $20-29$ & $30-39$ & $40-49$ & $50-59$ & $\geq 60$ & 0 \\
\hline No diagnosis & 2 & 0 & 0 & 0 & 1 & 0 & 3 & $0.021^{*}$ \\
\hline Organic disorder & 0 & 0 & 1 & 0 & 0 & 2 & 3 & $0.000^{*}$ \\
\hline Delirium & 1 & 2 & 5 & 4 & 5 & 2 & 19 & 0.246 \\
\hline Epilepsy & 0 & 0 & 3 & 0 & 0 & 0 & 3 & 0.315 \\
\hline Alcohol Use Disorder & 0 & 2 & 9 & 6 & 5 & 0 & 22 & 0.095 \\
\hline Opioid Use disorder & 0 & 1 & 0 & 0 & 0 & 0 & 1 & 0.506 \\
\hline Cannabis use disorder & 1 & 1 & 0 & 0 & 0 & 0 & 2 & 0.322 \\
\hline Psychosis & 0 & 0 & 3 & 1 & 1 & 0 & 5 & 0.709 \\
\hline Depression & 0 & 3 & 4 & 3 & 0 & 0 & 10 & 0.422 \\
\hline BPAD & 0 & 0 & 1 & 1 & 0 & 0 & 2 & 0.813 \\
\hline Anxiety Disorder & 0 & 1 & 1 & 0 & 0 & 0 & 2 & 0.835 \\
\hline Dissociative disorder & 2 & 3 & 0 & 0 & 0 & 0 & 5 & $0.022^{*}$ \\
\hline Insomnia & 0 & 0 & 1 & 0 & 0 & 0 & 1 & 0.866 \\
\hline Intentional self harm & 4 & 6 & 5 & 3 & 1 & 1 & 20 & 0.106 \\
\hline Others & 0 & 0 & 2 & 0 & 0 & 0 & 2 & 0.580 \\
\hline Total & 10 & 19 & 35 & 18 & 13 & 5 & 100 & \\
\hline
\end{tabular}

*: Statisticallv significant

Table 3: Distribution of subjects according to diagnosis and sex

\begin{tabular}{|c|c|c|c|c|}
\hline Diagnosis & Male & Female & Total & $\mathrm{p}$ value \\
\hline No diagnosis & 2 & 1 & 3 & 0.401 \\
\hline Organic disorder & 0 & 3 & 3 & 0.127 \\
\hline Delirium & 8 & 11 & 19 & 0.930 \\
\hline Epilepsy & 3 & 0 & 3 & $0.045^{*}$ \\
\hline $\begin{array}{l}\text { Alcohol Use } \\
\text { Disorder }\end{array}$ & 15 & 7 & 22 & $0.007^{*}$ \\
\hline Opioid Use disorder & 1 & 0 & 1 & 0.247 \\
\hline $\begin{array}{l}\text { Cannabis use } \\
\text { disorder }\end{array}$ & 2 & 0 & 2 & 0.100 \\
\hline Psychosis & 4 & 1 & 5 & 0.086 \\
\hline Depression & 2 & 8 & 10 & 0.121 \\
\hline BPAD & 0 & 2 & 2 & 0.215 \\
\hline Anxiety Disorder & 1 & 1 & 2 & 0.840 \\
\hline $\begin{array}{l}\text { Dissociative } \\
\text { disorder }\end{array}$ & 0 & 5 & 5 & $0.046^{*}$ \\
\hline Insomnia & 0 & 1 & 1 & 0.383 \\
\hline $\begin{array}{l}\text { Intentional self } \\
\text { harm }\end{array}$ & 3 & 17 & 20 & $0.011^{*}$ \\
\hline Others & 2 & 0 & 2 & 0.100 \\
\hline Total & 43 & 57 & 100 & \\
\hline
\end{tabular}

Table 4: Purpose Of referral

\begin{tabular}{|l|c|}
\hline Purpose of referral & Frequency/\% \\
\hline $\begin{array}{l}\text { For psychiatry diagnosis } \\
\text { and management }\end{array}$ & 45 \\
\hline $\begin{array}{l}\text { To rule out psychiatry } \\
\mathrm{d} / \mathrm{o}\end{array}$ & 18 \\
\hline Counselling & 24 \\
\hline Prevent suicide & 4 \\
\hline $\begin{array}{l}\text { Evaluation of psychiatry } \\
\text { medications }\end{array}$ & 7 \\
\hline $\begin{array}{l}\text { Associated psychiatry } \\
\text { management }\end{array}$ & 2 \\
\hline
\end{tabular}

The most common purpose of referral was for psychiatry diagnosis and management (45\%) followed by counselling (24\%) and to rule out psychiatry disorder (18\%). (Table 4 )

As shown in table 5 the most common reason for referral was predominant psychiatry symptoms exhibited by the patient (42\%) followed by psychiatric symptoms coexisting with physical illness (32\%) 
Table 5: Reason For Referral

\begin{tabular}{|l|c|}
\hline Reason for referral & Frequency/\% \\
\hline $\begin{array}{l}\text { Predominant psychiatric } \\
\text { symptoms }\end{array}$ & 42 \\
\hline $\begin{array}{l}\text { Psychiatric/Mental } \\
\text { symptoms coexisting with } \\
\text { physical illness }\end{array}$ & 32 \\
\hline No physical illness & 6 \\
\hline $\begin{array}{l}\text { Past history of psychiatric } \\
\text { disorder }\end{array}$ & 17 \\
\hline Organic illness & 100 \\
\hline Others & \\
\hline Total & \\
\hline
\end{tabular}

Similarly most common symptom exhibited by the patients for referral was self harm and violence $(25 \%)$ followed by altered sensorium (22\%) (Table 6)

Table 6: Most Common Symptom For Referral

\begin{tabular}{|l|c|}
\hline Symptoms & Frequency/\% \\
\hline Irrelevant talks & 7 \\
\hline Fainting spells & 5 \\
\hline Altered sensorium & 22 \\
\hline Somatic symptoms & 3 \\
\hline Sleep disturbance & 4 \\
\hline Suicidal ideations/acts & 3 \\
\hline Altered mood & 6 \\
\hline Anxiety symptoms & 2 \\
\hline Self harm and violence & 25 \\
\hline Seizure & 4 \\
\hline Others & 6 \\
\hline Disorientation & 13 \\
\hline Total & 100 \\
\hline
\end{tabular}

\section{DISCUSSION:}

In the present study, psychiatry referral rate from ICU was $7.87 \%$ with an average of 2.4 patients referred per day. Bhogale et al. ${ }^{15}$ found psychiatry referral rate of $1.97 \%$ which is considerably low to that of ours. Psychiatry morbidity in our study was found to be $8.11 \%$. In a study conducted in Singapore by Sim et al., ${ }^{8}$ psychiatric morbidity was found to be high
(36.4\%) but the study methodology considerably differed from that of ours. We used ICD-10 while the said study had used General Health Questionnaire (GHQ) ${ }^{16}$ to diagnose psychiatry disorders. It might have led to the difference in the findings of psychiatry morbidity in our study.

The mean age of the patients was $36.87+12.81$ years which was lower than the mean age of overall ICU patients of Nepal ${ }^{17}$ and other Asian countries including India ${ }^{18}$ and China. ${ }^{19}$ According to World Health Organization (WHO), half of all mental illness begin by the age of 14 and three-quarters by mid-20s. ${ }^{20}$ This younger age of onset of mental disorders might have contributed to a lower mean age in patients diagnosed with psychiatric disorders compared to that of overall patients admitted to ICU. In our study AUD and intention self harm were common diagnoses and patient of these disorders were generally younger in age. Fiftyseven percent of the patients were female. Female were more commonly diagnosed with dissociative disorder and ISH as compared to male and the association was statistically significant. Female preponderance in dissociative disorder is supported by various studies.21,22 Majority of the Nepalese population being Hindu by religion, our finding of $91.9 \%$ of the subjects being Hindu was expected and it has been observed in almost all the studies from Nepal. Fifty-nine percent of the subjects belonged from urban background. This finding may be due to the fact that the level of urbanization is increasing in Nepal and new municipalities are added up every year. ${ }^{23}$

In our study AUD was the most common diagnosis seen in $22 \%$ of subjects. AUD is common disorder referred for assessment to a psychiatrist from ICU15, emergency department $^{24}$ and from other departments. ${ }^{25}$ Substance use disorders including alcohol are one of the common disorders that need psychiatry evaluation and treatment. AUD being the most common disorder referred shows an increased awareness among general physicians regarding assessment and treatment of AUD by a psychiatrist. ISH was the second most common diagnosis present in $20 \%$ of subjects. ISH requires thorough examination by psychiatrist to assess for any underlying psychiatry disorder, to prevent any future 
attempts and for counselling purposes. It is common psychiatric disorder admitted in $\mathrm{ICU}^{9}$ and especially in a multispecialty hospital, it is also referred for psychiatric evaluation from various departments. ${ }^{25}$

Forty-five percent of the patients were referred for psychiatry diagnosis and management. Similarly 'patient demonstrating predominant psychiatry symptoms' was the most common reason for referral. This shows a heightened awareness among treating doctors identifying psychiatric symptoms and need for them to be evaluated and subsequently managed by psychiatrists. Altered sensorium was the most common symptoms for which the patients were referred which could have resulted due to various disorders including substance use disorder, delirium and use of different types of medications in ICU.

As this study was conducted on ICU patients who were referred for psychiatry assessment, there were some limitations which need to be addressed. First, non-referred patients were excluded for the study who might have had psychiatry symptoms or disorder. Second, it is a single center study so its external validity is limited. Third, 100 consecutive patients referred were accessed which lacked a system of randomization of the sample.

\section{CONCLUSION:}

The present study was undertaken to determine the prevalence and nature of psychiatric disorders in ICU. Multispecialty hospitals including government hospitals, private hospitals and teaching hospitals with ICU are increasing in Nepal. Most of the cases are admitted to ICU for critical and 24 hours care. ICU admission itself may be stressful to the patient and the primary disorder with various treatment regimen and use of multiple drugs and interventional procedures can lead to various psychiatric problems which are mostly neglected. Present study tried to analyze these issues and also highlighted the importance of psychiatric evaluation in ICU. The authors hope that the present study will motivate other researchers to carry out further studies in this subject so that more can be understood about this mostly neglected field of psychiatry.

\section{ACKNOWLEDGEMENT: None}

\section{CONFLICT OF INTEREST: None}

\section{REFERENCES:}

1. Berthelsen PG, Cronquist $M$. The first intensive care unit in the world: Copenhagen 1953. Acta anaesthesiologica Scandinavica. 2003 Nov;47(10):1190-5.

2. Scragg P, Jones A, Fauvel N. Psychological problems following ICU treatment. Anaesthesia. 2001;56(1):914.

3. Davydow DS, Gifford JM, Desai SV, Bienvenu OJ, Needham DM. Depression in general intensive care unit survivors: a systematic review. Intensive Care Medicine. 2009;35(5):796-809.

4. Davydow DS, Gifford JM, Desai SV, Needham DM, Bienvenu OJ. Posttraumatic stress disorder in general intensive care unit survivors: a systematic review. General Hospital Psychiatry. 2008;30(5):421-34.

5. Merikangas KR, Calkins ME, Burstein M, He JP, Chiavacci $R$, Lateef $T$, et al. Comorbidity of physical and mental disorders in the neurodevelopmental genomics cohort study. Pediatrics. 2015;135(4):e92738.

6. Walker ER, Druss BG. A public health perspective on mental and medical comorbidity. JAMA. 2016;316(10):1104-5.

7. Scott KM, Lim C, Al-Hamzawi A, Alonso J, Bruffaerts $R$, Caldas-de-Almeida JM, et al. Association of mental disorders with subsequent chronic physical conditions: world mental health surveys From 17 countries. JAMA psychiatry. 2016;73(2):150-8.

8. Sim K, Rajasoorya C, Lam KN, Chew LS, Chan YH. High prevalence of psychiatric morbidity in a medical intensive care unit. Singapore Medical Journal. 2001 Nov;42(11):522-5.

9. Gacouin A, Maamar A, Fillatre P, Sylvestre E, Dolan $M$, Le Tulzo $Y$, et al. Patients with preexisting psychiatric disorders admitted to ICU: a descriptive and retrospective cohort study. Annals of Intensive Care. 2017 Dec;7(1):1.

10. Girard TD, Pandharipande PP, Ely EW. Delirium in the intensive care unit. Critical Care. 2008;12 Suppl 3:S3.

11. Suchyta MR, Beck CJ, Key CW, Jephson A, Hopkins $R O$. Substance dependence and psychiatric disorders are related to outcomes in a mixed ICU population. Intensive Care Medicine. 2008 Dec;34(12):2264-7.

12. Acharya SP. Critical care medicine in Nepal: where are we? International Health. 2013 Jun;5(2):92-5.

13. Koirala S, Ghimire A, Sharma A, Bhattarai B. ICU admission and outcomes in a community-based tertiary care hospital: an audit of one year. Health Renaissance. 2011;9(2):83-7.

14. The ICD-10 classification of mental and behavioral disorders diagnostic criteria for research. Geneva: 
World Health Organization; 1993.

15. Bhogale GS, Nayak RB, Dsouza M, Chate SS, Banahatti MB. A cross-sectional descriptive study of Prevalence and nature of psychiatric referrals from intensive care units in a multispecialty hospital. Indian Journal of Psychological Medicine. 2011 Jul;33(2):16771.

16. Goldberg DP. The detection of psychiatric illness by questionnaire. Oxford University Press; 1972.

17. Vaidya PR, Shrestha RR. Outcome of the Patients Admitted in New Intensive Care Unit, Bir Hospital: Five years review. Postgraduate Medical Journal of NAMS. 2015;15(1):1-5.

18. Divatia J, Amin P, Ramakrishnan N, Kapadia F, Todi $S$, Sahu $S$, et al. Intensive care in India: The Indian intensive care case mix and practice patterns study. Indian Journal of Critical Care Medicine. 2016;20(4):216-225.

19. Du B, An Y, Kang Y, Yu X, Zhao M, Ma X, et al. Characteristics of critically ill patients in ICUs in mainland China. Critical Care Medicine. 2013 Jan;41(1):84-92.

20. World Health Organization Child and adolescent mental health [Internet]. World Health Organization; 2018 [cited 2018 Nov 21]. Available from: https://www.who.int/mental_health/maternalchild/child_adolescent/en/

21. Deka K, Chaudhury P, Bora K, Kalita P. A study of clinical correlates and socio-demographic profile in conversion disorder. Indian Journal of Psychiatry. 2007;49(3):205.

22. Chaturvedi SK, Desai G, Shaligram D. Dissociative disorders in a psychiatric institute in India - a selected review and patterns over a decade. International Journal of Social Psychiatry. 2010 Sep 17;56(5):533-9.

23. Regmi LK. An overview of population growth trends of Nepal. Journal of Institute of Science and Technology. 2014;19(1):57-61.

24. Ranjan S, Poudel R, Pandey P. Pattern of psychiatric referral from emergency of a tertiary level hospital in Nepal. Journal of Universal College of Medical Sciences. 2015;3(2):5-9.

25. Ranjan S, Poudel R, Pandey P. Consultation-liaison psychiatry in tertiary level hospital in Nepal. Health Renaissance. 2014;12(3):170-4. 